\title{
Descolonizações dos circuitos artísticos audiovisuais: experiências micropolíticas entre o projeto de alcance global “The Giant Step” e os índios Makuxi da Amazônia
}

Leila Adriana Baptaglin ${ }^{1}$ Lisiane Machado Aguiar ${ }^{2}$ Jaider Esbell $^{3}$

\section{Introdução}

O Brasil foi a terceira nação a receber a visita do artista Viliam Mauritz ${ }^{4}$, que iniciou sua jornada na praia de Sandgate, Brisbane na Austrália e teve a segunda edição em Kaposmero, na Hungria.

Imagem 01: Intervenções artísticas.

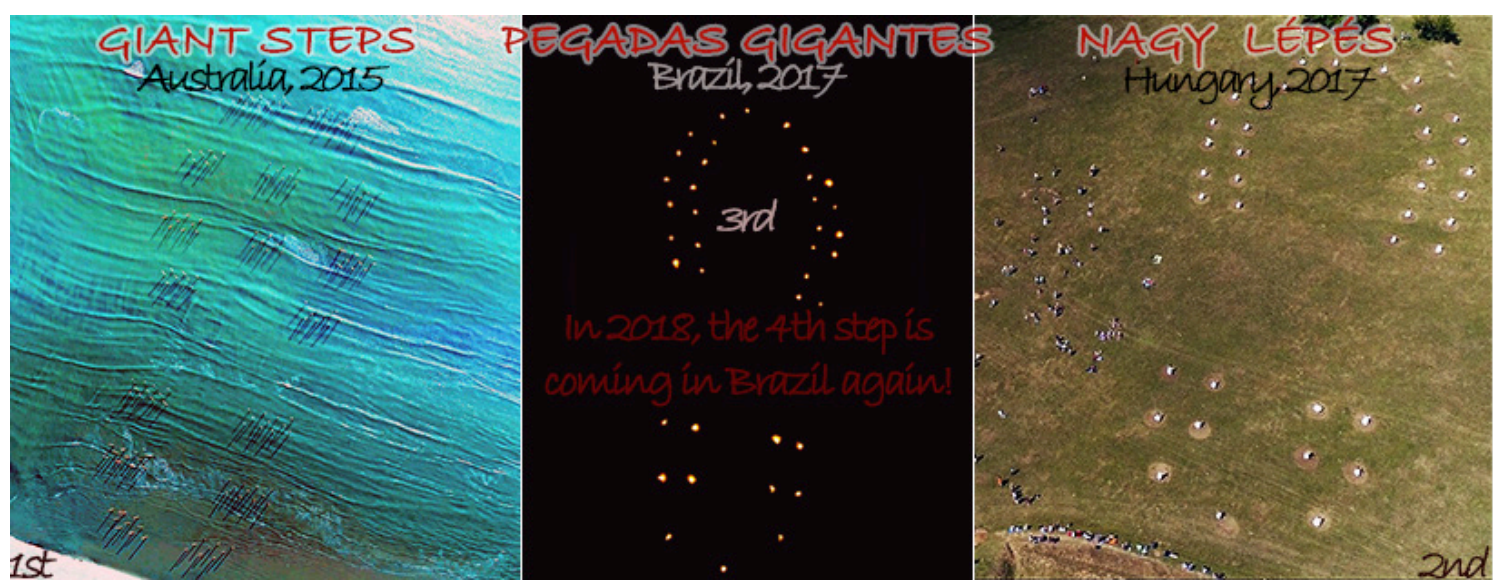

Fonte: www.thegiantsteps.org

$\mathrm{Na}$ terra indígena do povo $\mathrm{Makuxi}^{5}$, o evento aconteceu nos dias 6,7 e 8 de outubro de 2017. A ideia central da intervenção artística foi a de conectar pessoas a realidades pares diferentes, com o mínimo de impacto ambiental e o máximo de repercussão com o uso de ferramentas audiovisuais em mídias digitais. A proposta do artista é de encontrar em diversas partes do mundo, artistas produtores que também

\footnotetext{
1 Universidade Federal de Roraima, Brasil.

${ }^{2}$ Universidade Federal do rio Grande do Sul (UFRGS).

3 Artista indígena da etnia Makuxi.

4 Para mais informações no site do projeto. Disponível em: www.thegiantsteps.org

5 Raposa I, faz parte da terra indígena Raposa Serra do Sol é uma área situada no nordeste do estado brasileiro de Roraima fazendo fronteira com a Venezuela e a Guiana. É destinada à posse permanente dos grupos indígenas Ingaricós, Macuxis, Patamonas, Taurepangues e Uapixanas.
} 
façam agenciamentos artísticos em seus locais de origem mobilizando estruturas e pessoas para a grande interação.

Com o formato de uma pegada gigante com proporções a partir de 100 x 45 metros, que remete à ideia de um caminhar itinerante e de um ser maior que sai conectando temas globais com desafios locais para evidenciar aspectos culturais dos nativos em agenciamento com suas artes.

A visualização da pegada só pode ser percebida com a produção de filmes que serão editados contendo de 3 e 10 minutos. Drones foram usados para captar as imagens aéreas durante o dia e a noite. As imagens diurnas, mostraram indígenas Makuxi dançando o parixara - dança ritual ancestral em uma coreografia coletiva preparada especialmente para a ocasião. As cenas noturnas mostraram 39 fogueiras que foram acesas ao mesmo tempo para mostrar a pegada gigante e a relação espiritual e usual dos Makuxi com o fogo e a lenha. Foi usado lenha da árvore Mirixi, não por coincidência, mas pela relação desta com a comunidade.

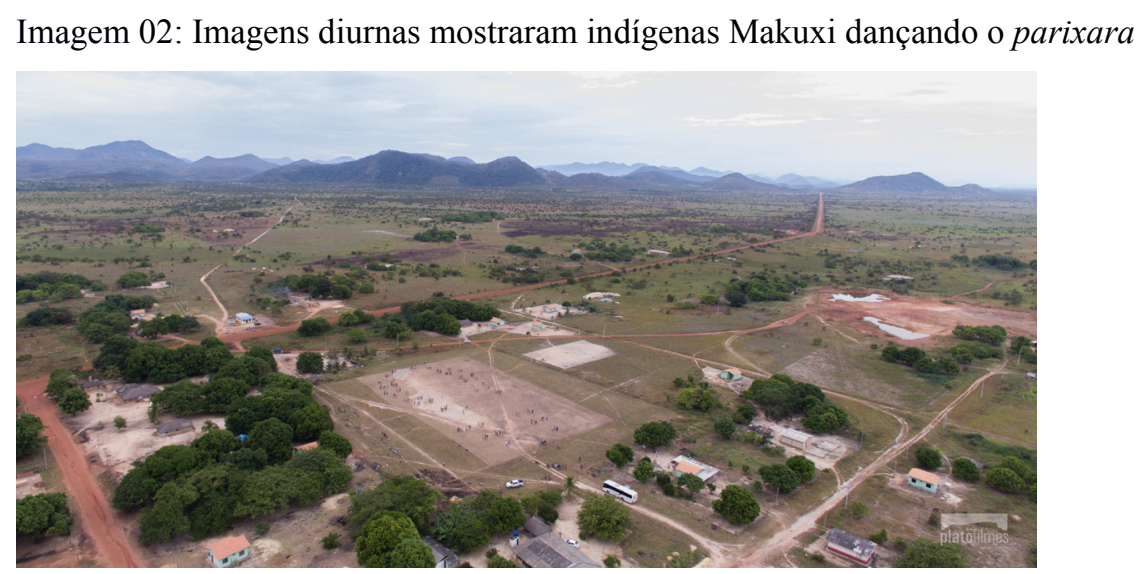

Fonte: Thiago Briglia (2017)

Imagem 03: Imagens noturnas mostraram 39 fogueiras para formar a pegada gigante 


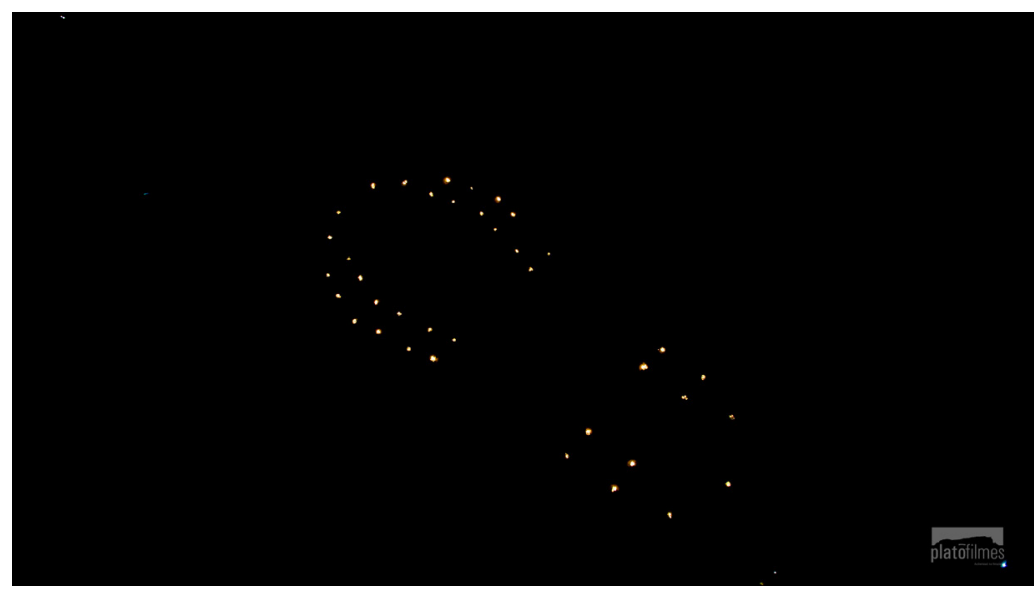

Fonte: Thiago Briglia (2017)

Entendemos que esse tipo de produção artística que conta com o auxílio do audiovisual necessita de uma articulação comunicacional para funcionar enquanto tal. Situação essa que perpassa, para além do produto, por outros elementos do Circuito da Cultura e, neste caso específico, do Circuito da Arte.

Se tomarmos o circuito da arte num fluxo como o da experiência da vida veremos que esse apresenta uma ruptura com a representação clássica recognitiva para fazer dele potência criadora. Isso significa suspender os sentidos já criados por modelos colonialistas a serem aplicados, e possibilitar o desenvolvimento de diferentes experiências artísticas ao livrar-se de orientações de parâmetros hegemônicos. Buscando ir além de uma colonialidade do ser, ou seja, o resultado da "experiência vivida da colonização e seu impacto na linguagem" (Maldonado Torres, 2007: 130), procuramos investigar como o uso do audiovisual em intervenções artísticas descolonializam os circuitos da arte contemporânea por meio das mídias digitais.

$\mathrm{O}$ investigador com um posicionamento epistemológico descolonizador (Maldonado-Torres, 2007; Sousa Santos, 2007; Mignolo, 2010; Smith, 2016) afasta-se de circuitos imagéticos universais, de verdades absolutas, de uma postura positivista e funcionalista para desenvolver sua arte de forma processual que pretendem reconstruir os acontecimentos ao invés de representá-los. Ou seja, não há a separação radical entre uma vida biológica, política, econômica, o que existe são imanências e a coexistência de cada um destes campos em relação aos outros.

Desse modo, buscamos problematizar como as intervenções artísticas de alcance global reterritorializam o desenvolvimento/envolvimento artístico de comunidades indígenas ampliando a possibilidade de expansão de sua arte em diferentes espaços 
culturais por meio do audiovisual e de sua circulação em mídias digitais. Para isso, contemplamos, nesse artigo, três linhas de problematização. Abordamos inicialmente os sentidos criados pela arte indígena da cultura Makuxi durante a intervenção "The Giant Step". Em segundo lugar, problematizamos como o uso do audiovisual em intervenções artísticas descolonializam e desterritorializam os circuitos da arte contemporânea com suas formas de expor em relação com as distintas esferas das mídias digitais. Em terceiro lugar, aproveitamos as considerações finais para propor que o circuito da arte necessita de modificações, pois o processo de mediação passa a requerer estratégias que interliguem o artista-obra ao expectador-consumidor para que o Circuito da Arte se estabeleça. Apresentando assim, a necessidade de rupturas dos padrões configurados nos entornos do trabalho com a Cultura e a Arte.

\section{Arte indígena da cultura Makuxi apresentada no "The Giant Step"}

A comunidade indígena Raposa I, localizada na Terra indígena Raposa Serra do Sol é composta por cerca de 960 habitantes. Formada em sua maioria, por indígenas da etnia Makuxi que vivem no lavrado. Em diferentes contextos, a terra indígena da Raposa Serra do Sol é referência, e busca, por vários meios, manter-se viva. Fazer arte indígena contextual foi uma das estratégicas que a comunidade desenvolveu para divulgar sua cultura. As atividades artesanais, artísticas e espirituais sempre foram mantidas. Secular, a comunidade mantém sua identidade em alternância de fluxos que perpassam por identidade e autonomia. Nos últimos anos, especialmente após a homologação da reserva, a comunidade volta ao destaque com atividades culturais que priorizam práticas e saberes ancestrais em resistência a novos depreciativos da cultura de massa (álcool e resíduos não orgânicos).

Na comunidade indígena Makuxi, a materialização performática central da obra foi feita com os Parixaras, entidades centrais na cultura Makuxi, que dançam o Parixara. Ao dançar o Parixara o Makuxi bate firme os pés no chão, assim, ressaltam o valor das pegadas firmes em diferentes leituras quais possam ser contextualizadas entre realidades e visões extrapoladas sobre a vida coletiva na Terra.

Imagem 04: Makuxi dançando o Parixara 


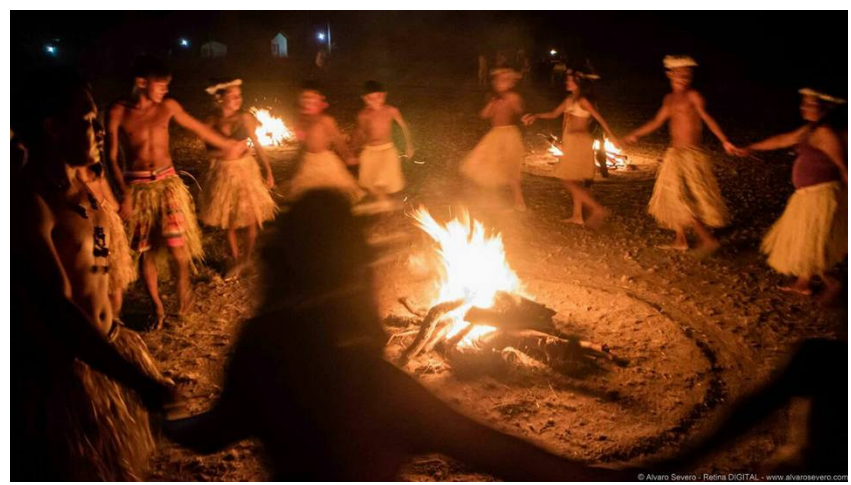

Fonte: Alvaro Severo (2017)

A dança parixara faz parte de um ritual de agradecimento à natureza sendo o grande chamamento para um olhar maior para a saúde da Terra como mãe maior da humanidade e de todos os seres é parte do conceito central da peça artística na comunidade indígena no Brasil.

Em parceria com o artista Jaider Esbell, índio Makuxi da região da Raposa, a proposta foi apresentada para toda a comunidade que decidiu em reunião interna receber os artistas e seus convidados, bem como aceitou o desafio de fazer acontecer a interação por meio de um verdadeiro festival de cultural Makuxi durante os três dias da intervenção artística.

Todas as atividades de interação cultural foram registradas para o acervo audiovisual e memória da comunidade e parte será editada para formatar filmes que serão os produtos imediatos de projeção midiática para o passo seguinte: a conexão dessa experiência com as diferentes esferas das mídias digitais.

A comunidade indígena se mobilizou para receber, materializar visualmente a obra de arte e acompanhar os seus desdobramentos. Foi a primeira vez que a comunidade indígena recebeu uma atividade de cunho internacional, com arte global, mostrando o local. Pela primeira vez, também a comunidade foi envolvida como parceira na realização de uma obra de arte com um artista de outro país.

A programação envolveu interação cultural livre com feiras, oficinas, caminhadas no campo, expedições na natureza e apresentações culturais realizadas pelos próprios indígenas. Artistas e comunidade receberam outros artistas indígenas como convidados especiais para a consagração do trabalho coletivo de arte.

Artistas locais foram convidados para celebrar o ato como uma conquista autônoma do esforço maior da arte e da resistência da arte indígena. Esse feito é 
carregado de significados e o maior sem dúvida é a capacidade política de organização da comunidade em agenciar uma arte coletiva de alcance global. A performance coletiva é de fato um chamamento para questões culturais. Neste sentido, entendemos que no campo das Artes, a subjetivação não está apenas na produção, mas em outros âmbitos como os o uso de diferentes audiovisuais em mídias digitais.

A existência de novos agentes, como o curador (cuja subjetividade, se considerado o poder que possui, pode vir a resultar em exposições cujos temas e questões sejam estranhos aos artistas que delas participem), gera fatalmente uma tensão entre a produção artística e esses poderes habituados à primazia que de forma institucional lhes foi concedida (COCCHIARALE, 2004: 70).

De acordo com o artista Jaider Esbell a intervenção artística na sua comunidade inova na possibilidade de dar visibilidade a essas linguagens artísticas que vem sendo produzidas em espaços comunitários e educacionais minoritários. "Na prática, a realização da escultura gigante na comunidade da Raposa I é um feito histórico e enigmático. $\mathrm{O}$ modo como foi feita a abordagem, a presença clara da comunidade em todas as etapas, diferencia este de qualquer feito antes realizado"6.

Imagem 05 e 06: Utilização do Drone para a Intervenção artística “The Giant Step”

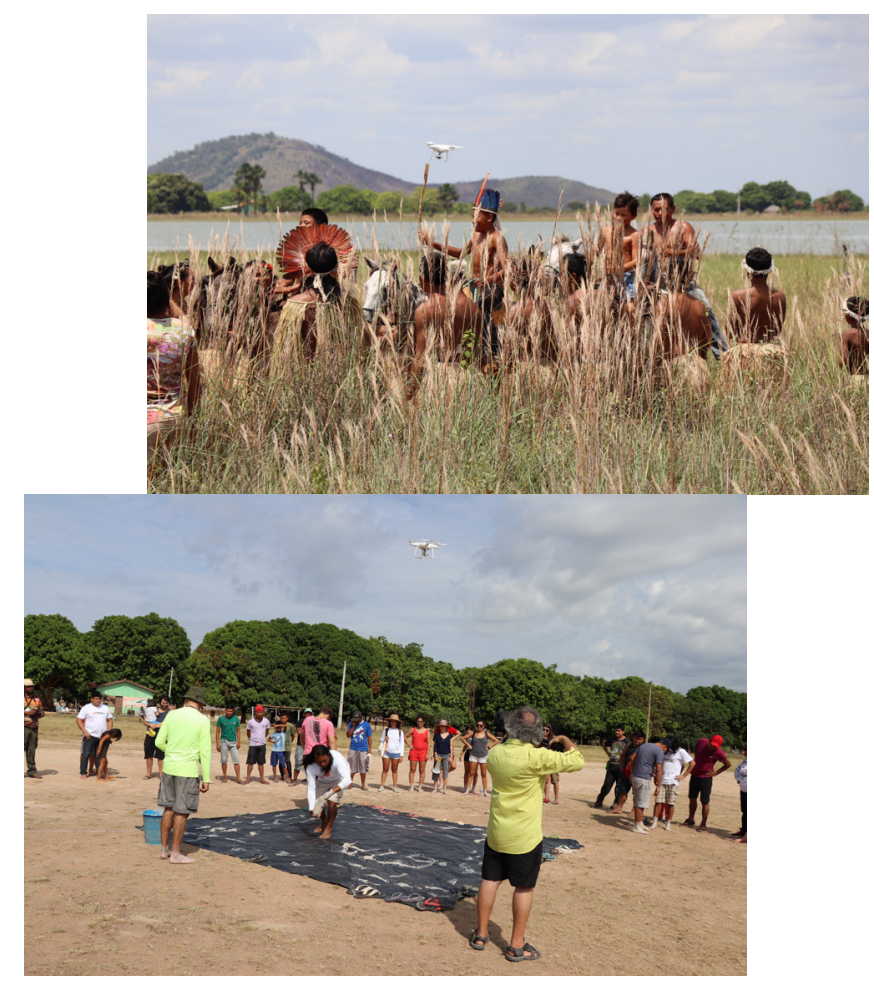

6 Jaider Esbell, índio Makuxi da região da Raposa em sua rede social do Facebook. 
Fonte: Lisiane M. Aguiar (2017)

O conhecimento artístico e histórico das linguagens indígenas amplia o repertório de valorização de sua produção justificando sua produção e inserção em diferentes espaços artísticos e conta com o auxílio audiovisual nas mídias digitais.

Dessa forma, a subjetividade do expectador passa pertencer a obra e, consequentemente ao lugar. Esta apropriação da obra pelo sujeito e do sujeito pela obra é realizada de diferentes formas, mas especificamente, a partir do século XXI, com as conexões via rede.

Cocchiarale (2004: 70), nos coloca que as redes eletrônicas recobrem uma parte significativa do mundo, no entanto, são "[...] apenas um resultado e um instrumento das desterritorializações em cascata que estão na raiz de nosso mundo". Apresenta-se assim como um dos meios de apreciação e comunicação entre obra e expectador, mas não o único.

O contato físico e a visualidade ainda apresentam uma força significativa no processo comunicacional artístico. O impacto da obra expostas nos espaços públicos acrescenta ao artista e, também ao expectador a sensação de êxtase e euforia próprios da apropriação artística. Assim podemos sinalizar que a obra passa a explorar um outro espaço de ocupação que começa a ser consolidado e erigido pelo artista e expectador.

Trabalhar a intervenção artística é trabalhar com as concepções de lugar, simbologia, estesia, presentes tanto no artista como no expectador, ambos construindo uma sintonia de ideais que compactuam na construção do social. Um social cheio de especificidades e subjetividades próprias da sintonia estabelecida na Arte contemporânea. Situação esta extremamente complexa ao tratarmos de um lugar social como o estado brasileiro de Roraima (onde se encontra a comunidade indígena Raposa - Serra do Sol), que ainda carece de experiências com exposições artísticas e ocupações do lugar cotidiano, do espaço urbano, como galerias ou museus para suas obras.

Além de seu valor estético, as intervenções artísticas contemporâneas trazem à tona problemáticas e reflexões sobre o ambiente social. Assim, segundo Silva (2015: $05)$ “'[...] a percepção das intervenções contemporâneas está conectada com os espaços e tempos de uma cidade. Muito além de observar mudanças geográficas, territoriais e "cronológicas" de uma cidade é preciso entender suas composições, suas durações e seus ritmos cotidianos". Estas intervenções com públicos variados, instiga o olhar 
crítico para os acontecimentos locais. Mas, como investigar os processos micropolíticos de produção de linguagens artísticas audiovisuais em confluência com a alteridade dos movimentos culturais?

O posicionamento epistemológico, nesse artigo, ocorre pela lógica dos sentidos na filosofia da diferença. Assim, a micropolítica é entendida como o processo de produção de conhecimento a partir das relações de saber-poder. Não se quer saber apenas "o quê?", mas "de que modo" e, principalmente, "como" determinado saber artístico e não outro está sendo trabalhado.

Para isso, metodologicamente compomos uma problematização críticaheurística-interpretativa das estratégias de relações de poder em composição com o campo de saber. Partimos da perspectiva que a discussão sobre intervenções artísticas merece ser reconhecida como elemento vital para reflexões sobre o ambiente social. Deve ser entendida mais amplamente do que a simples descrição de observação. Ela envolve também os importantes aspectos conceituais, éticos, estéticos e políticos.

Assim, deve-se ter em conta que a linguagem audiovisual pode ser entendida a partir de diferentes perspectivas que se inter-relacionam e se articulam nos processos de investigação. O ponto de vista mais comum associa o uso de som e imagem na composição de produtos midiáticos que requisitam os sentidos da audição e da visão para sua percepção. Se essas entradas permitem certas delimitações nesse campo, não dão conta de sua complexidade e, nesse sentido, das suas multiplicidades (Deleuze e Guattari, 1995). Afinal, o estudo do audiovisual na inserção do trabalho artístico pode se constituir como linguagem e discurso, numa complexa relação entre a cultura, a imagem, a técnica e atravessadas pela ética e pela estética. Tanto prevendo espaços para consensos, divergências, padronizações, sociabilidades e trocas simbólicas, como também para usos, apropriações, configurações, convergências, experimentações e inovação sobre formatos, suportes e tecnologias.

Nesse processo, é possível pensar o audiovisual como uma esfera de virtualidade e atualizações que potencializa devires de diversas ordens, já não há espaços para o hegemônico, ou seja, a pesquisa teórico-metodológica deve ser capaz de trabalhar com a diferença e com a pluralidade de um campo complexo, que alimenta e é alimentado por outros campos, engendrando inter-relações constantes de tensão e distensão sobre a técnica, os discursos e culturas em potencial. 
Para avançar sobre as especificidades dessas multiplicidades audiovisuais no campo artístico temos que refletir não apenas sobre as possibilidades epistêmicas, mas igualmente sobre as suas mudanças no circuito da arte. Buscamos, então, acompanhar os processos de produção das intervenções artísticas - como foi o caso da realização do “The Giant Step" na comunidade indígena Raposa - Serra do Sol, desnaturalizando o que é legitimado como a intervenção, rastreando as suas relações e analisando os sentidos que as orientam dentro do campo da linguagem ao se utilizar o audiovisual na composição da obra.

\section{O uso do audiovisual em intervenções artísticas}

Como podemos inferir através desses pontos que uma analítica das relações de saber-poder se refere à diversas linhas de forças micropolíticas (institucionais, discursivas, históricas, políticas, culturais, econômicas, entre outras) desde que sejam entendidas enquanto práticas. Dessa maneira, uma problemática gerada a partir dessa perspectiva busca operar processualmente não como algo que possa ser identificado com referências e indivíduos específicos, mas que conecta a todos. É um agenciamento que se processa micropolíticamente entre o saber, o poder e a subjetivação. $O$ significado só existe a partir do momento em que foi enunciado, passando a fazer parte de um ou mais discursos.

Entre o saber, o poder e a subjetivação há um processo de produção de conhecimento que conecta-se inevitavelmente a uma política, ou seja, cria e atualiza o possível. Nessa política há dimensões coexistentes que não se opõem, mas que se diferenciam: uma macropolítica que é molar com planos de formas e sistemas de sobrecodificações; e, uma micropolítica que é molecular com plano de fluxos e linhas de fuga.

Observamos que este campo convoca constantes transformações tanto no plano molar quanto molecular, o que implica agenciamentos dos processos de produção. Para Guattari e Rolnik (2013: 133) "a questão da micropolítica é a de como reproduzimos (ou não), os modos de subjetivação dominante (...)". Assim, mesmo naquilo que ganha visibilidade como hegemônico há sempre espaço de criação. O poder deixa de ter uma 
relação direta com o Estado (ele deixa de ser um órgão único de poder) e passa a ter uma existência nas formas de exercício do poder. A micropolítica não parte do centro para a periferia ou do macro para o micro, ou seja, não parte seus estudos do Estado para procurar até onde se estende nas dimensões mais baixas da sociedade. Assim, podemos pensar no o audiovisual pode se constituir como linguagem e discurso, numa complexa relação entre a técnica e a cultura, atravessadas pela estética e pela ética.

Podemos considerar o audiovisual como conformador de um campo complexo, que alimenta e é alimentado por outros campos, engendrando inter-relações constantes de tensão e distensão sobre a técnica, os discursos e culturas em potencial. Nesse processo, é possível prever espaços para consensos, divergências, padronizações, sociabilidades e trocas simbólicas, mas também para usos, apropriações, configurações, convergências, experimentações e inovação sobre formatos, suportes e tecnologias.

Como, então o uso do audiovisual em intervenções artísticas com a cultura indígena desterritorializa e descolonializa os circuitos da arte contemporânea com suas formas de expor em relação com as distintas esferas das mídias digitais?

Isso ocorre, pois as artes passam a vincular-se ao público de forma diferenciada exigindo dos processos de mediação o conhecimento e a interação com o sujeito consumidor.

Imagem 07 e 08: Divulgação das intervenções

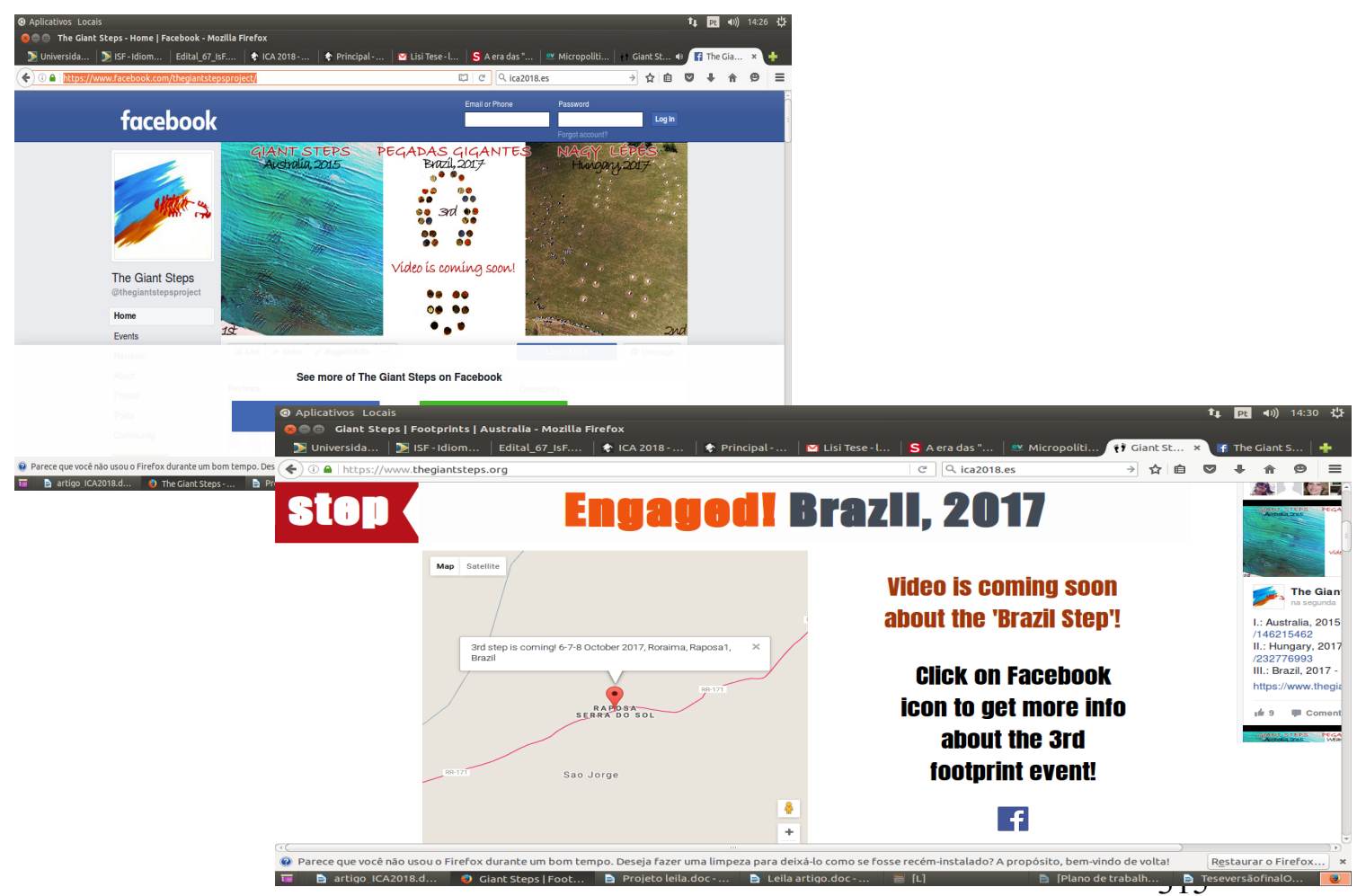

Iluminuras, Porto Alegre, v. 20, n. 49, p. 306-322, maio, 2019. 
Fonte:

I Australia, 2015-https://vimeo.com/146215462

II.:Hungary, $2017 \mathrm{https://vimeo.com/232776993}$

III.: Brazil, 2017 - https://www.thegiantsteps.org/project/iii-brazil-2017

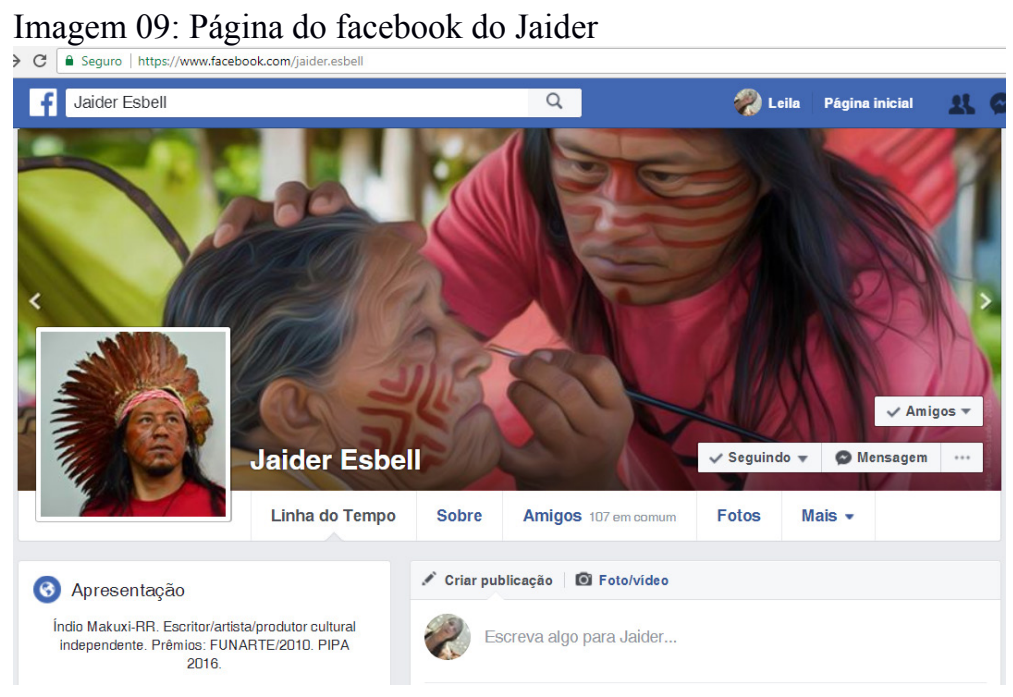

Fonte: www.facebook.com/jaider.esbell

Estes passos nos mostram que o artista e o expectador necessitam de outras formas de interação para a apreciação e o consumo da Arte. Isso pode ser evidenciado principalmente pela existência de outros locais e de outros atores existentes no circuito da Arte não restringindo-se ao espaço do Museu e aos atores antes envolvidos, mas sim, adentrando em espaços não formais e nos meios digitais. A existência deste cenário proporciona a necessidade da mediação condizente e, é nesta perspectiva que a avaliação do processo apresenta-se como fundamental para que o circuito seja completo e atenda as necessidades do artista e do expectador.

Este processo e mediação é necessário, mas requer do profissional mediador conhecimentos que the possibilite dialogar com cada sujeito e suas peculiaridades sendo este um trabalho bastante complexo. Um trabalho de conhecimento e valorização sociocultural do sujeito e dos seus espaços de formação. 
Neste sentido, a mediação e a elaboração da obra passam a ser vistos com um olhar voltado para a compreensão da arte como um todo e não apenas na interpretação da obra a partir de questionamentos incipientes.

A liberdade de interpretação e a não "prisão" às regras faz com que a imaginação e a interpretação possibilitem a criatividade e ampliação de horizontes visuais. E, a ampliação de espaços de apreciação da arte vem proporcionando este desenvolvimento cultura ampliando possibilidades de construção de conhecimentos para o sujeito. Com isso, o processo de mediação em diferentes espaços culturais vem passando por modificações adequando-se as transformações e informatizações sociais a fim de atender as demandas que vem surgindo.

Trabalhar com as especificidades de uma intervenção artística requer do mediador preparação e compreensão do contexto artístico contemporâneo. Assim, além dos museus, nos espaços informais de mídias digitais e nas outras situações de exposição da obra de Arte no contexto contemporâneo temos diferentes concepções de cultura que desencadeiam diferentes tipos de mediação as quais, longe de serem homogêneas, aparecem muito dependentes de seu contexto.

As intervenções artísticas que fazem sua difusão por meio das mídias digitais apresentam-se como uma das linguagens contemporâneas que extrapolam o lugar da arte até então consolidado: o museu e as galerias. Lugares esses que, na região amazônica e, em especial no Estado de Roraima, ainda não podem ser considerados consolidados visto que, em Roraima o único museu existente está fechado e, os lugares de exposição de obras de Arte ainda são bastante restritos limitando-se a algumas galerias de instituições privadas e/ou galerias particulares de artistas locais.

Assim, as intervenções artísticas que utilizam o espaço digital em associação com o audiovisual constituem-se em uma linguagem artística que passa a ganhar corpo a partir do momento em que levam a arte para os espaços públicos dando a possibilidade de apreciação pelos diferentes sujeitos. Aguça, com isso, um outro olhar para o processo comunicacional a ser construído, haja vista a ideologia proposta nas intervenções artísticas, como no caso de "The Giant Step" e, a recepção de um público vasto nem sempre exposto à apreciação artística.

Referente ao objeto arte, conforme considerações de Leirner (1984: 06), “[...] podemos então entender que, mesmo o objeto recolhido praticamente pronto, precisa ser apropriado pelo artista, para ganhar novos significados e tornar-se objeto de arte". A 
apropriação de objetos cotidianos, expostos em lugares cotidianos, passa a estimular no sujeito a criticidade sobre o conceito do que é Arte. Isso porque o expectador não é mais apenas o crítico e apreciador de arte e, em muitas situações, o conceito e o processo de apropriação do objeto não foram ainda internalizados pelo sujeito, haja vista a recente inserção e trabalho deste na produção artística contemporânea e, ainda mais na divulgação em lugares públicos.

A produção digital/Ciberarte apresenta-se como uma gama bastante ampla de nomenclaturas surgidas pela inserção da informática na produção artística: o e-mail arte, a vídeo arte, a web arte. Na contemporaneidade, a partir da manipulação dos espaços e das novas tecnologias digitais, surgem composições artísticas que vão sendo construídas a partir dos paradigmas das mídias digitais - com interatividade, hibridismo e fragmentação.

A Ciberarte apropria-se da expressividade do ciberespaço construindo assim ambientes virtuais que aguçam o expectador a ativam correntes cibernéticas de interlocução do artista, obra e expectador conectando-os e tornando-os um só (DOMINGUES, 2002).

As intervenções surgem como práticas de intervir no espaço urbano em suas mais variadas intensidades. No cenário atual as intervenções aparecem não apenas como uma arte, mas como uma nova maneira de se comunicar. As intervenções, a partir da modificação/reorganização do espaço urbano propõe uma estruturação crítica do pensar do expectador sendo ela utilizada a partir de diferentes técnicas e linguagens.

As linguagens artísticas contemporâneas supracitadas apresentam um caráter de intervenção a partir do momento em que passam a incidir no espaço urbano ocasionando a necessidade de compreensão e outros meios de comunicação com o expectador.

Estas produções artísticas contemporâneas passam a integrar o espaço digital de fácil acesso, envolvendo a subjetividade do expectador e intervindo em seu lugarcomum de forma artística. Assim, as intervenções artísticas urbanas, em um campo de produção artística contemporânea, proporcionam lembrar o que Cauquelin (2005) nos mostra ao referir-se ao processo comunicacional. Passamos a vivenciar uma inevitável mistura de papéis: produtor/artista, distribuidor/comunicador e consumidor/expectador. Estes sujeitos, antes com características e funções delimitadas, não mais possuem 
atividades específicas e, este é um dos grandes desafios a serem consolidados para uma melhor compreensão da produção artística indígena no estado roraimense.

A lógica de consumo (ainda não implementada, mas com algumas sinalizações dentro das poucas consolidações de um circuito de arte em Roraima) passa a sofrer alterações e incrustações devido aos incrementos tecnológicos e as novas demandas alicerçadas pela criação de outras linguagens artísticas que extrapolam o espaço de exposição do museu e das galerias adentrando ao lugar público (GONÇALVES, 2017).

Assim, a necessidade de outros profissionais, que ainda não fazem parte de um cenário competitivo e qualificado em Roraima, é agregada a este circuito - e/ou o artista passa a ter que se apropriar destes outros segmentos no intuito de dar a conhecer sua produção.

Estas mudanças estabelecem um câmbio irreversível na relação da arte com o expectador, clamando por um olhar mais aguçado para os tempos e espaços de apropriação no circuito da arte, em especial, o das linguagens artísticas contemporâneas e, no nosso caso, das intervenções artísticas que passam a ser expressas nas redes sociais.

\section{Considerações para uma proposta: modificações no Circuito da Arte}

Na interlocução do Campo da Arte com a Comunicação e a Cultura, podemos considerar que a intervenção artística se apresenta como manifestação de um elo entre estes campos a qual proporciona situações em que há a rápida comunicação da obra para com o expectador e, é neste viés que os novos atores do circuito da arte passam a interagir.

O circuito da cultura em que diferentes atores passam a fazer parte de um sistema operador/operativo da Cultura fornece elementos importantes para trilharmos uma possível cartografia do Circuito da Arte.

No texto/leitura, adentrando ao campo comunicacional da produção artística, o artista apropria-se de suas habilidades técnicas de produção para abstrair e expressar para o expectador utilizando-se de diferentes elementos. Contudo, neste momento a apropriação dos conhecimentos artísticos e do espaço urbano estabelecem uma vinculação direta com o processo de mediação a partir do momento em que a recepção da obra adquire um status de produção de sentido pelo expectador. 
Esta leitura autônoma evidencia um risco eminente de apropriação equivocada da mensagem estabelecida pelo artista. Segundo Escoteguy (2007: 121) "o risco é assumir a autonomia da leitura em oposição a autoridade do texto, suprimindo ainda a produção do que está sendo consumido".

$\mathrm{Na}$ intervenção artística com a cultura indígena, a autoridade do texto é deixada de lado assim como a compreensão advinda de um processo de mediação que auxilie o leitor/expectador a compreensão da obra. Passamos assim a verificar duas condicionalidades de leitor/apreciador o que busca compreender "o que a obra diz de mim" e/ou "o que a obra quer dizer". Ambas as perspectivas são plausíveis, mas requerem uma percepção aguçada do expectador, haja vista que no espaço digital a presença do mediador é dispensada/inexistente.

Conforme Escosteguy (2007: 121), o processo de texto/leitura requer assim, “[...] uma conexão com as práticas de grupos sociais e os textos que estão em circulação, realizando uma análise sócio-histórica de elementos culturais que estejam ativos em meios sociais particulares"

A compreensão das Culturas Vividas do artista e do expectador são fundamentais para que haja conexão e consumo da obra. Consumo aqui é vinculado ao processo de apropriação simbólica do conceito pelo expectador e não necessariamente o consumo em termos materiais da obra. Artista e expectador necessitam estabelecer uma relação que apresente interesses comuns, que os interligue suplantando assim a simples vinculação e o consumo da obra do artista pelo expectador. Isso ocorre, mesmo aquele sendo um sujeito com relações sociais, culturais e históricas distintas das expressas pelo artista.

O artista necessita do conhecimento do lugar a ser exposto e do público a ser atingido a fim de que sua construção ideológica seja consumida pelo expectador.

O consumo deixa de ser a troca/compra de bens materiais e passa a ser espaço de diálogo entre sujeitos e entre obra e expectador adentrando ao processo de apropriação de culturas e simbologias.

Além destes elementos do circuito cultural, o processo de financiamento da produção artística também passa por modificações. Há algumas décadas o financiamento de obras e em especial, o financiamento cultural era quase que exclusivo do Estado ou de alguns mecenas. Hoje, a iniciativa privada começa a ganhar espaço e a vincular-se a prerrogativa de arte como negócio, situação que incita a preocupação 
sobre as produções artísticas haja vista que os patrocínios/financiamentos contemporâneos podem acabar por atender mais aos interesses da iniciativa cultural privada do que ao artista.

Mesmo diante de modificações na estrutura do Circuito da Arte, realizadas devido as necessidades de contexto, ainda dispomos de uma estrutura que se apresenta vinculada a alguns padrões de consumo repassados à sociedade a partir da Revolução Industrial, do advento do Capitalismo e da Cultura de Massa. Situação esta presente, haja vista que a arte representa a sociedade e apresenta o que nela há de mais sincero e incrustado. É neste processo de representação que assentamos nossas proposições.

Trabalhar com uma construção artística contemporânea requer, portanto, uma aproximação conceitual bastante estruturada em valores e normas construídos socialmente. Verificamos que a cultura indígena é um elemento significativo na construção dos saberes amazônicos, contudo, estes ainda carecem de uma apropriação adequada para serem transpostos ao nível de produção artística e da consolidação de um Circuito da Arte.

\section{Referências}

CAUQUELIN, Anne. Arte Contemporânea: uma introdução. São Paulo: Martins, 2005.

COCCHIARALE, Fernando. A (outra) Arte Contemporânea Brasileira: intervenções urbanas micropolíticas. Revista do Programa de pós-graduação em artes visuais EBA, UFRJ, 2004.

DELEUZE, Gilles; GUATTARI, Félix. Mil Platôs - capitalismo e esquizofrenia. Rio de Janeiro: Ed. 34, 1995.

ESCOTEGUY, Ana Carolina. Circuito da cultura/circuito de comunicação: um protocolo analítico de integração da produção e recepção. Revista Comunicação, Mídia e Consumo. São Paulo. Vol. 4.Nov. 2007.

DOMINGUES, Diana (org.). A arte no século XXI: A humanização das tecnologias. São Paulo: UNESP, 1997.

GONÇALVES, Tainá Ribeiro (2017): Culturas e identidades em Roraima: um olhar para as representações pictóricas de artistas do curso de artes visuais/UFRR. Dissertação de mestrado em Letras. Roraima. UFRR, 2017.

GUATTARI, Félix; ROLNIK, Suely. Micropolítica: cartografias do desejo. Petrópolis: Vozes, 2013. 
LEIRNER, Nelson. Exponha-se à arte. São Paulo: Galeria de Arte São Paulo, 1984.

MALDONADO-TORRES, Nelson. Sobre la colonialidade del ser: contribuciones al desarrollo de un concepto, en CASTRO-GÓMEZ S., GROSFOGUEL R. (eds). $O$ giro decolonial. Reflexiones para una diversidad epistémica más allá del capitalismo global. Bogotá, Iesco-Pensar-Siglo del Hombre Editores, 2007.

MIGNOLO, Walter. Desobediencia epistémica: retórica de la modernidad, lógica de la colonialidade y gramática de la descolonialidad. Buenos Aires: Edições del Signo, 2010 .

SILVA, Eloenes Lima (2015): Intervenções artísticas em espaços públicos e pedagogias da cidade: possibilidade de pesquisa. $37^{a}$ Reunião Nacional da ANPEd, UFSC Florianópolis, 2015.

SMITH, Linda Tuhiwai. A descolonizar las metodologías. Investigación y pueblos indígenas. Chile: Lom Ediciones, 2016.

Recebido 23/04/2019

Aprovado 28/05/2019 